RESEARCH ARTICLE

\title{
Modal Logic before Kripke
}

\author{
Max Cresswell*
}

Received: 27 October 2018 / Accepted: 30 November 2018

Abstract: 100 years ago C.I. Lewis published A Survey of Symbolic Logic, which included an axiom system for a notion of implication which was 'stricter' than that found in Whitehead and Russell's Principia Mathematica. As far as I can tell little notice was taken of this until 1930 when Oskar Becker provided some additional axioms which led Lewis in Symbolic Logic (written with C.H. Langford, 1932) to revise the system he had produced in 1918, and list five systems which could be obtained using Becker's suggested formulae. The present paper reviews the development of modal logic both before and after 1932, up to 1959 looking at, among other work, Becker's 1930 article and Robert Feys's articles in 1937 and 1950. I will then make some comments on the completeness results for S5 found in Bayart and Kripke in 1959; and I will finally look at how modal logic reached New Zealand in the early 1950s in the work of Arthur Prior.

Keywords: Modal logic; history of modal logic; C. I. Lewis; strict implication; Saul Kripke

\section{Introduction}

In recent times modal logic has been seen as the logic of relational frames, a development which took place in the early 1960s. In order to reinforce the

\footnotetext{
${ }^{*}$ Victoria University of Wellington

Philosophy (HPPI), Victoria University of Wellington, PO Box 600, Wellington 6140, New Zealand

\max.cresswell@vuw.ac.nz

(C) The Author. Journal compilation (C) The Editorial Board, Organon F.
} 
importance of this change it is timely to reflect on what modal logic was like up to that time. Such reflections are especially appropriate in that 2018 marks the centenary of the publication of C.I. Lewis's Survey of Symbolic Logic which represents the first presentation of a formal axiomatic system of modal logic.

\section{Principia Mathematica (PM) 1910}

Although modal logic was studied since the time of Aristotle, and was revived in the late 19th century by Hugh McColl, the modern development of the subject really begins with C.I. Lewis's dissatisfaction with some of the 'paradoxical' sentences found in Whitehead and Russell 1910. These include:

(1) $p \supset(q \supset p)$

$(2) \sim p \supset(p \supset q)$

(3) $(p \supset q) \vee(q \supset p)$

(1) and (2) can be read as claiming that if $p$ is true then it is implied by every proposition, and if it is false it implies every proposition. (3) claims that of any two propositions one implies the other. Beginning in 1912 C.I. Lewis objected that these theorems conflict with the interpretation of $\supset$ as 'implies'.

\section{C.I. Lewis Mind 1912, 1914, Journal of Philosophy, 1913, 1914}

Lewis makes a distinction between an implication which holds materially and one which holds necessarily or strictly. The first article in Mind (Lewis 1912), after exhibiting (1)-(3) as what Lewis regards as defects in a theory of implication, concentrates on pointing out that you can understand implication as $\sim p \vee q$ provided that you understand the disjunction intensionally i.e. as holding necessarily. (Lewis 1912, 523) On p. 526 he calls the implication used in the "Algebra of logic"1 material' and contrasts it with his own 'inferential'

\footnotetext{
${ }^{1}$ In footnote 1 on p. 522 he instances PM as 'the most economical development of the calculus of propositions' in particular with its definition of $p \supset q$ as $\sim p \vee q$.
} 
or "strict" implication.' In the second of the articles in Mind (Lewis 1914a) he introduces two symbols for intensional $(\mathrm{V})$ and extensional $(+)$ disjunction respectively, though he only uses one symbol for implication $(\supset)$, insisting on its ambiguity. Although in the 1912 paper he speaks of an intensional disjunction as one which is necessarily true, he does not adopt any symbol for necessity. (If $\vee$ is intensional you can of course define the necessity of $p$ as $p \vee p$, but Lewis does not do so.) In neither of these articles does Lewis attempt anything like an axiomatisation of the logic of strict implication, though on p. 243 of (Lewis 1914a) he does provide a list of formulae which are valid, using $\supset$ for material implication and + for material disjunction; and contrasting these formulae with some corresponding formulae in a language in which $\supset$ is strict implication and both $\vee$ and + appear. The two articles from the Journal of Philosophy (Lewis 1913, 1914b) have a slightly different focus. The 1913 article lists a large number (35) of valid formulae in PM which Lewis regards as questionable when $\supset$ is interpreted as implication. As in his other articles Lewis uses $\supset$ for strict implication and $\vee$ for strict disjunction. As in (Lewis 1914a), in (Lewis 1914b) he uses + for material disjunction, but in this article he introduces $<$ for material implication. He also uses $\sim$ for impossibility and - for negation. On p. 591 of (Lewis 1914b) he does produce an axiom set, though two of the axioms are defective when $\supset$ is understood intensionally. One is $(p \supset q) \supset((q \supset r) \supset(p \supset r))$, which, when added to the other axioms, reduces each strict operator to its material counterpart. ${ }^{2}$ It's clear that what Lewis is trying to do is retain as much of PM as he can without running into what he thinks of as its paradoxical consequences. He clearly thinks that material implication does not reflect what he supposes ordinary logicians (uncorrupted by truth-functional logic) think of as the relation of implication.

\section{Lewis 1918}

(Lewis 1918) is the first axiomatic presentation of modern modal logic. ${ }^{3}$ What

\footnotetext{
${ }^{2}$ Problems like this are discussed in (Parry 1968). Parry notes on p. 126 that in the 1912 paper Lewis accepts the equivalence of $(p \vee(q \vee r))$ and $(q \vee(p \vee r))$ even when $\vee$ is a strict disjunction, and comments in footnote 39: "These mistakes, long since corrected, show the fallibility of logical intuition." Parry's chapter provides a thorough survey of Lewis's modal logic, and for that reason the present paper concentrates on the work of others at that time, in particular works which are not available, or not easily accessible in English.

${ }^{3}$ For an elaboration of this claim see (Parry 1968).
}

Organon F 26 (3) 2019: 323-339 
Lewis says is "Various studies toward this system have appeared in Mind and the Journal of Philosophy. ... But the complete system has not previously been printed." (Lewis 1918, 291, fn. 1).

The chapter on strict implication $(-3)$ is only a small part of the book. In that chapter Lewis does not do any metalogic, and even definitions seem to be regarded as object-language formulae. ${ }^{4}$

(Lewis 1918) takes impossibility $(\sim)$ as primitive, and defines $p \multimap q$ to mean that it is impossible that $p$ should be true without $q$ 's being true too. In 1918 - is still used for 'not' and $\sim$ for impossibility, so $-\sim p$ means that $p$ is possible and $\sim-p$ means that $p$ is necessary. Lewis uses juxtaposition for conjunction, but I have used the now common $\wedge$ and therefore write Lewis's definition as $p-3 q={ }_{\text {def }} \sim(p \wedge-q) .^{5}$ What you then find is a collection of axioms (Lewis 1918, 291ff.) of which the first five are no more than strict but conjunctive versions of axioms of PM. Specifically Lewis's axioms are: ${ }^{6}$

$$
\begin{aligned}
& 1.1(p \wedge q) \dashv(q \wedge p) \\
& 1.2(q \wedge p) \dashv p \\
& 1.3 p \neg(p \wedge p) \\
& 1.4(p \wedge(q \wedge r)) \neg(q \wedge(p \wedge r)) \\
& 1.5 p \neg--p^{7} \\
& 1.6((p \dashv q) \wedge(q \neg r)) \dashv(p \dashv r) \\
& 1.7 \sim p \dashv-p
\end{aligned}
$$

\footnotetext{
${ }^{4} \mathrm{~A}$ criticism of these early papers is found in (Wiener 1916). Although Wiener does not put the point in exactly this way his defence of Russell against Lewis could easily be seen as pointing out that when we are giving an account in the metalanguage of implication we are claiming that for any formulae $\alpha$ and $\beta$, $\alpha$ implies $\beta$ when $\alpha \supset \beta$ is valid, which is to say that it is true no matter what formulae $\alpha$ and $\beta$ are. Or, if you prefer, either $\alpha$ is false or $\beta$ is true, no matter what values are given to its propositional variables. Lewis seems unaware of this way of describing the situation. Here and elsewhere in the paper I use $\alpha, \beta$ etc. as metalogical variables for well-formed formulae (wff) of the relevant object language. The need for making such a distinction seems not to have been recognised by these earlier writers.

${ }^{5}$ In doing so it must be remembered that on p. 293 of (Lewis 1918), in 1.04, Lewis uses the symbol $\wedge$, not for conjunction, but for strict disjunction. In 1.05, he uses + for material disjunction.

${ }^{6}$ In addition to using $\wedge$ for conjunction in place of Lewis's juxtaposition, I have inserted parentheses.

${ }^{7}$ This axiom is repeated in the list on p. 493 of (Lewis and Langford 1932), but was proved to be redundant in (McKinsey 1934). Lewis notes McKinsey's result in the 1959 Appendix (Appendix III) to (Lewis and Langford 1932) on p. 503.
} 


\section{$1.8(p \dashv q)=(\sim q \dashv \sim p)$}

It's not difficult to see how these axioms arose. The idea is that PM's theorems also hold when the main operator is strict, in the sense that, for instance, when $\supset$ is replaced by -3 the result will still be valid. ${ }^{8} 1.6$ states the transitivity of 3. 1.7 says that impossibility implies falsity. 1.8 is in many ways the most interesting. In the first place it was shewn by E.L. Post to lead to $\sim p=-p$, and was replaced, in Lewis 1920, by ${ }^{9}$

$$
1.8^{*}(p \multimap q) \dashv(\sim q \jmath \sim p)
$$

But even $1.8^{*}$ was one which later caused Lewis some trouble. It's not difficult to see why. In the antecedent both variables are in the scope of a -3 which is itself only in the scope of the main operator, while in the consequent both the variables are in the scope of $\sim$ (which for Lewis is a modal operator) which in turn is in the scope of a -3 which is itself in the scope of a modal operator.

Except for Lewis's 1920 correction to 1.8 little notice appears to have been taken of his work until a 1930 article by Oskar Becker. ${ }^{10}$

\section{$5 \quad$ Becker 1930}

Although in the Survey Lewis had taken the one-place impossibility operator as the only modal primitive, for which he used $\sim$, his principal interest was in the defined operator 3 . I mentioned above that the $p$ and $q$ in the consequent of $1.8^{*}$ are in the scope of three operators: one occurrence of $\sim$ and two occurrences of -3 . (Just as $p$ in $\sim \sim p$ is in the scope of two modal operators, which prevents its elimination by a double negation rule.). In more recent notation, with $\square$ (or $L$ ) for necessity, ${ }^{11}$ and $\diamond$ (or $M$ ) for possibility, Lewis's $\sim \sim p$ is equivalent to $\square \nabla p,-$ would be $\diamond, \sim-$ would be $\square, \sim-\sim-$ would

\footnotetext{
${ }^{8}$ Thus, for instance, not only is $-p \supset(p \supset q)$ valid, so is $-p-3(p \supset q)$, but not of course $-p-3(p-3 q)$.

${ }^{9}$ The label $1.8^{*}$ is given by (Becker 1930, 504) (but using < for strict implication). In (Lewis 1918) it is 2.2 on p. 297.

${ }^{10}$ There are a few exceptions. As well as (Wiener 1916) mentioned in footnote 4 above there is an article by E. J. Nelson (1930) on what have come to be called the 'paradoxes of strict implication' - that an impossible proposition strictly implies every proposition, and that a necessary proposition is implied by every proposition. (See Lewis 1918, 506: 3.52 and 3.55.) Although this topic has caused philosophical controversy I am not concerned with it in this paper.

${ }^{11}$ In the time in question modal notation was somewhat fluid, and, except when commenting specifically on notational matters I have used Fitch's symbol $\square$ for necessity and Lewis's symbol $\diamond$ for possibility. The first published use of $\square$ is in (Barcan 1946).
}

Organon F 26 (3) 2019: 323-339 
be $\square \square,-\sim-\sim$ would be $\diamond \diamond$, and so on. These sequences of operators are what Becker called 'modalities', and in particular, where one modal operator is inside the scope of another he called them 'iterated' or 'complex' modalities. (Becker 1930, 502) comments that:

The more complicated modalities are not handled by Lewis. It is striking that the iterations of impossibility are mentioned. ${ }^{12}$

By this he means that Lewis's axioms do not guarantee the reduction of iterated modalities. So (Becker 1930, 508) says:

We therefore add to the Lewis axioms the new axiom 1.9

$$
1.9-\sim p<\sim \sim p^{13}
$$

A few pages later he introduces two further axioms:

$$
1.91 p<\sim \sim p(\text { p. 513) }
$$

$$
1.92 \sim-p<\sim-\sim-p
$$

In current notation 1.9 is equivalent to $\diamond p-\neg \nabla p, 1.91$ is $p-\neg \square \nabla p$, and 1.92 is $\square p-3 \square \square p$. These axioms are all ones considered by (Lewis 1932). 1.91 is the proper axiom of S5 and 1.92 of $\mathbf{S 4} 1.91$ is the Brouwerian axiom. Becker's principles led Lewis to write the appendix to the 1932 book with Langford, in which he set out a number of modal systems of increasing strength.

\section{$6 \quad$ Lewis and Langford $1932(\mathrm{~L} \& \mathrm{~L})$}

I won't say much about (Lewis and Langford 1932) since it is well known, and surveys of the various Lewis systems exist all over the place. In this work Lewis takes possibility, which he writes as $\diamond$, as the basic modal notion, and defines $p \triangleleft q$ as $\sim \diamond(p \wedge \sim q)$. ( $\sim$ is now the regular negation, not impossibility as in Lewis 1918.) By 1932 Lewis had been convinced that even axiom 1.8* was too strong, and opted for something weaker. In an appendix Lewis sets out five systems which he calls S1-S5. The system of (Lewis 1918) is the

\footnotetext{
${ }^{12}$ This translation is by Jacques Riche.

${ }^{13}$ Becker's symbol for strict implication is <. I am omitting superfluous parentheses.
} 
system he calls $\mathbf{S 3}$, and it is the presence of $1.8^{*}$ in $\mathbf{S 3}$ which appears to have worried him. The system he favoured was the one he called S2. In the 1932 book he includes a proof that $\mathbf{S 1}$ is weaker than $\mathbf{S 2}$, and he is clear that $\mathbf{S 3}$ is stronger than he wanted, but at the time of writing L\&L he had no proof that S3 was stronger than S2, and used $\mathbf{S 1}$ as a 'fallback' position in case S2 should contain S3. (Parry 1934 proves that S3 is stronger than S2, and Parry 1939 is a study of the modality patterns of S3.)

Although L\&L was published in 1932 the next two articles appear to have been written in ignorance of that work, and so do the papers they refer to. They mostly use the notation of (Lewis 1918), and I will follow them in this (though they sometimes use $<$ instead of -3 ). But I will refer to the systems S3, S4 and S5 even though these names were only introduced in an appendix to L\&L.

\section{$7 \quad$ Gödel 1933}

In a one page plus three lines article, Gödel provides an axiomatisation of the system now called S4. Although Gödel is aware of Lewis's earlier work, and also aware of Becker's work, and of the work of W.T. Parry, he does not yet seem to be familiar with L\&L. From the perspective of modal logic the main feature of Gödel's paper is to axiomatise $\mathbf{S} \mathbf{4}$ by shortcutting the separate postulation of strict versions of the axioms of PM, and replacing them with a rule which says that if a formula is a theorem then so is that formula preceded by a necessity operator which Gödel writes as $B$. This rule is added to an axiomatisation of the classical (non-modal) propositional calculus, together with the axioms:

- $B p \rightarrow p$

- $B p \rightarrow((B(p \rightarrow q) \rightarrow B q)$

- $B p \rightarrow B B p$

In these axioms $\rightarrow$ is the symbol for material implication (Whitehead and Russell's つ) used in (Hilbert and Ackermann 1928).

One might wonder how Gödel came to consider an axiomatisation with such a rule. I owe the following conjecture to a discussion with Rob Goldblatt. 
Gödel's paper is concerned to shew how to interpret intuitionistic logic with the aid of $B$ as a 'provability' operator. In intuitionistic logic, mathematical truths - represented by formulae which can be 'asserted' - only exist because they have been proved. It therefore seems natural to add a rule which explicitly states this. As far as I understand, Gödel was not a modal logician, though his article does make the link with Lewis's system extended by an axiom of Becker's which is equivalent to Gödel's $B p \rightarrow B B p$. Nevertheless, although Gödel at that stage may not have been familiar with Lewis and Langford's book he was familiar with (Becker 1930), since he had reviewed it in (Gödel 1931), and therefore he would have been familiar with (Lewis 1918), at least to the extent that Becker represents Lewis.

Gödel cites (Parry 1933) ${ }^{14}$ as evidence that the system that he, Gödel, has just presented is indeed the system of (Lewis 1918) provided that it is extended by one of Becker's axioms. Gödel is correct that Lewis's system (S3) with the addition of $N p<N N p$ does axiomatise his (Gödel's) system. This axiom is Becker's 1.92 on p. 514, which gets you S4. (Parry 1933) however is concerned with Becker's 1.9, which is what is one form of the proper S5 axiom. Parry's purpose is to provide a decision procedure by conjunctive normal form for first-degree modal formulae - formulae in which no modal operator is within the scope of any other modal operator. Parry does not himself prove that Becker's 1.9 guarantees that every formula can be reduced to first degree, though he does add a footnote acknowledging the appearance of (Wajsberg 1933), in which the reduction of every formula to the relevant normal form is established with the aid of 1.9. Since such a reduction is not possible in S4, nothing in (Parry 1933) helps (Gödel 1933). So in all likelihood it may be accidental that Gödel refers us to (Parry 1933), and probable that the connection with modal logic is incidental to Gödel's aim. It is perhaps significant that the item immediately following (Parry 1933) is a paper by Gödel, though unconnected with modal logic. ${ }^{15}$

\section{$8 \quad$ Wajsberg 1933}

Wajsberg concentrates on $\mathbf{S} 5$ rather than $\mathbf{S} 4$. He uses a reduction to a normal form, and gives an interpretation in an 'extended' logic of classes which con-

\footnotetext{
${ }^{14}$ (Parry 1933) is Gödel's Parry (1933a). Gödel's Parry (1933) is my (Parry 1934).

${ }^{15}$ Much of the information in this section, and indeed the whole paper, is based on material collected by Jacques Riche, to whom I am deeply indebted.
} 
tains an operator on a class $A$ which gives the universe class $U$ when $A=U$ and the empty class $\emptyset$ when $A \neq U$. Wajsberg axiomatises this calculus in a way which can be seen as a set of axioms for S5 (and he notes this). In a sense then this can be said to constitute the first completeness proof in modal logic. It does however provide completeness only for S5. One feature that Wajsberg's work does illustrate is that there is a difference between reducing modalities, strings of $\square, \diamond$ and $\sim$, and modal functions, formulae with modal operators in them. Though he does not use the name 1.9 or attribute the axiom to Becker Wajsberg's work shews that with Becker's 1.9 you can not only reduce all modalities to six, but you can reduce all modal functions to formulae of first degree. This contrasts with $\mathbf{S} \mathbf{4}$ where, although there are only finitely many distinct modalities, modal functions are not always reducible to first degree.

Axiom 1.9 was first published in (Becker 1930), but from a footnote on p. 492 of L\&L it seems that Wajsberg had seen its importance before Becker's work had appeared. Lewis in this footnote is commenting on some matrices which can be used to distinguish the various systems he (Lewis) is putting forward. Lewis writes:

Groups II and III, below, were transmitted to Mr. Lewis by Dr. M. Wajsberg, of the University of Warsaw, in 1927. Dr. Wajsberg's letter also contained the first proof ever given that the System of Strict Implication is not reducible to Material Implication, as well as the outline of a system which is equivalent to that deducible from the postulates of Strict Implication with the addition of the postulate later suggested in Becker's paper and cited below as C11. ${ }^{16}$ It is to be hoped that this and other important work of Dr. Wajsberg will be published shortly.

\section{$9 \quad$ Feys 1937}

In 1937 Robert Feys produced a survey of modal systems. Much of Feys's article is in the spirit of Lewis in looking at which laws of the non-modal propositional calculus still hold when the symbols are interpreted 'strictly'

\footnotetext{
${ }^{16} \mathrm{C} 11$, in the notation of (Lewis and Langford 1932) is $\diamond p-3 \sim \diamond \sim \diamond p$, and is the characteristic axiom of the system Lewis called S5. In the notation of (Lewis 1918), it is $-\sim p-3 \sim \sim p$. In Becker and in Wajsberg it is $-\sim p<\sim \sim p$
}

Organon F 26 (3) 2019: 323-339 
and which do not. There is however an important difference. Feys seems to be the first to notice that you can treat modal logic as a collection of systems, all based on classical logic, but in which the modal operators can be given a variety of interpretations, and each system reflects some particular interpretation. Unlike Lewis, Feys seems to feel that it is not at all an easy matter to decide on just which logic is the 'correct' one, and points out that mainstream logic concentrates on non-modal operators. Feys sees the need to justify considering modality against those who think that 'the logic of truth and falsity is enough'. Here are some extracts from $\S 1$ of Feys's paper. ${ }^{17}$

The idea of a logic of modalities is as old as logic itself.

When, two thousand years after Aristotle, logistics resumes its work to give it mathematical rigor, the form it will adopt is that of a logic of truth and falsity, almost such as the Stoics had conceived it. In this restricted form it will prove susceptible of a tangible and adequate expression by symbols of which Principia Mathematica remains the model.

But such a methodical limitation does not eliminate the problems of philosophy, and even of the sciences, which are stated in terms of modalities. It is impossible to reason about causality, about the very value of deductions, without resorting to the idea of necessity and to those correlative to it, the idea of possible, of contingent.

Feys then sets out the nature of the axiomatic method, contrasting the situation in modal logic with that in non-modal propositional logic which he calls 'the logic of true and false'. In the case of the logic of true and false there is another method available that is to say we can study the logic of material implication by the method of truth-tables, and therefore such logic may be held not to require the axiomatic method. By contrast, in 1937 this method seemed the only one available for modal logic.

An axiomatic presentation does not require you to attach any meaning to the formulae. Feys first lists a set of axioms known to be sufficient for the

\footnotetext{
${ }^{17}$ I am using a translation by Jacques Riche, but have altered Feys's own rather idiosyncratic notation to a notation with $\diamond$ and $\square$ for the possibility and necessity operators.
} 
propositional calculus followed by three modal axioms. With $\diamond$ for possibility and $\square$ for necessity these are: ${ }^{18}$

- $p \supset \diamond p(23.11)$

- $\square p \equiv \sim \diamond \sim p(24.1)$

- $(\square(p \supset q) \wedge \square p) \supset \square q(25.3)$

together with the rules:

- A logical law remains true if one substitutes for a variable $p, q, r$, wherever it appears, the same function containing modalities. (22.3)

- If $p$ and $p \supset q$ are logical laws, $q$ is a logical law. ${ }^{19}$ (13.42)

- From a logical law $p$ one can conclude to a logical law $\square p$. (What is tautologically true is tautologically necessary). ${ }^{20}$ (25.2)

In $\S 20$ Feys shows awareness of the difference between Lewis's way of proceeding, in which the axioms are all stated in terms of strict implication, and Gödel's way of proceeding:

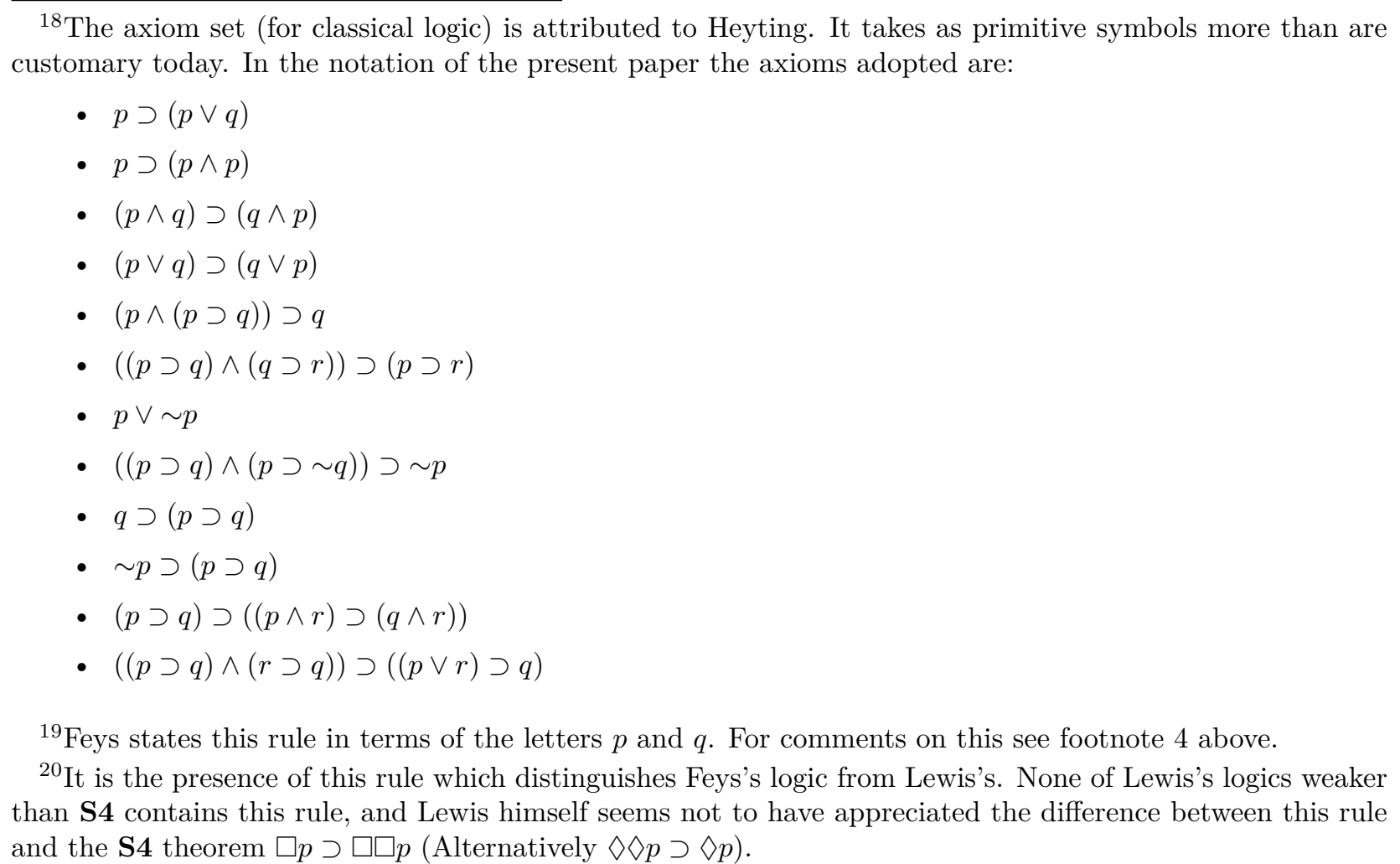

Organon F 26 (3) 2019: 323-339 
Two methods make it possible to relate these kinds of logics to a system of postulates (it seems to us obvious to call them logics of the Aristotelian modalities). The logics of Strict Implication avoid presupposing the logic of truth and falsity; their postulates introduce, simultaneously with the true and the false, other modalities. We will follow another path, indicated in particular by Gödel. We will start from the logic of true and false and we will complete it with postulates that will introduce the other Aristotelian modalities.

Feys dropped Gödel's $\mathbf{S} 4$ axiom $\square p \supset \square \square p$ to give the system now called $\mathbf{T}$. In the 1937 paper Feys seems unaware that he has produced a modal system which is none of Lewis's S1- S5.

\section{McKinsey and Carnap}

In 1945/46 both J.C.C McKinsey, and Rudolf Carnap produced accounts of modality which justify particular Lewis systems. (I have discussed these in Cresswell 2013.) McKinsey's characterised S4 and Carnap's S5. ${ }^{21}$ They were however not really flexible enough to provide the generality that we have come to expect for the multiplicity of systems which have been studied after the development of the relational semantics for modal logic. ${ }^{22}$

\section{Feys 1950}

In 1950 Feys explicitly presents a survey of the systems in (Lewis and Langford 1932), together with two systems $\mathbf{S} \mathbf{1}^{0}$ and $\mathbf{S} \mathbf{2}^{0}$, which are like $\mathbf{S} \mathbf{1}$ and $\mathbf{S} \mathbf{2}$ except that they lack the axiom $p \triangleleft \diamond p$.

As in the 1937 paper a large amount of the 1950 paper is to list the various respects in which the theorems of the various systems of strict implication do or do not match up with the theorems of the ordinary non-modal propositional calculus. In footnote 13 of this article Feys makes some remarks about

\footnotetext{
${ }^{21}$ Carnap's 1946 study is in fact very similar to Wajsberg's and on p. 41 in footnote 8 Carnap acknowledges his debt to Wajsberg's 1933 article.

${ }^{22}$ Hans Reichenbach also discussed modalities (for instance in Reichenbach 1954), but his work stands somewhat outside the development of mainstream modal logic.
} 
the system now called T, which is the system presented in (Feys 1937). The footnote refers to von Wright, who mentions material from his then forthcoming (von Wright 1951b), in which the system is called M. As Feys notes, his system (T) is taken from (Gödel 1933) by omitting the $\mathbf{S} 4$ axiom. Gödel's own paper only discusses a system which is (deductively equivalent to) one of Lewis's, and so may have caused Feys to miss the crucial fact that his own system is not one of Lewis's.

\section{A.N. Prior}

One of the clearest introductions to modal logic in the 1950s occurs in (Prior 1955). Prior was interested in modal logic from the early $1950 \mathrm{~s} .{ }^{23}$ In the Craft of Formal Logic, a manuscript from 1952, Prior shews an awareness both of (Lewis and Langford 1932) and of (Feys 1950), though he is more concerned to discuss how problems which can be expressed in 'Professor Feys's notation' had already been discussed by earlier thinkers, particularly in the 18th century. So although he is becoming familiar with modal logic Prior does not yet seem to have made it his own. He does adopt Feys's symbol $L$ for necessity, which goes well with the modal operator $M$, as well as the Eukasiewicz symbols for the truth-functional operators which he almost certainly got from Bochenski. He was familiar with the work of G.H. von Wright, who, in (von Wright 1951a), produces a system of deontic logic which Prior refers to in an article published in the Australasian Journal of Philosophy later in that same year. ${ }^{24}$ In that article Prior appears to suggest that his own interests do not yet run to an appreciation of modern Modal/Deontic logic. His familiarity with modal logic certainly emerges in (Prior 1952) where he imagines what amounts to a two world model in which four truth values correspond to true in both, true in the first and false in the second, false in the first and true in the second, and false in both. He then points out that there will be formulae whose validity in that model depends on there being only two worlds. But perhaps Prior's strongest contribution to modal logic was in his John Locke Lectures at Oxford in 1956 (published as Prior 1957) in which he shewed how to interpret modal logic as a logic of time. For he established in that work that different assumptions about temporal ordering could lead to different systems

\footnotetext{
${ }^{23}$ Mary Prior stresses the importance of Prior's teacher at the University of Otago, J.N. Findlay, whom she reports as using (Lewis and Langford 1932) in a course in 1940.

${ }^{24}$ (Prior 1951). Page references are to the reprint in (Prior 1976).
}

Organon F 26 (3) 2019: 323-339 
of modality. (Prior 1967, 27) speaks of a communication from Saul Kripke pointing out that $\mathbf{S} 4$ was too weak to be the logic of futurity because it allowed branching futures. This insight led inexorably to the semantic study of modal logic in terms of a set of indices ordered by a relation which could satisfy different conditions. Prior returned to New Zealand after his year at Oxford in 1956, but at the end of 1958 took up a chair in Manchester.

\section{Bayart 1958, 1959}

In 1959 Saul Kripke produced a definition of validity, in terms of classes of models, for quantificational S5. ${ }^{25}$ This was published in The Journal of Symbolic Logic for that year. What was less noticed was that in Logique et Analyse in 1958 Arnould Bayart produced a definition of validity for quantificational S5 in which he used a set of 'possible worlds', acknowledging Leibniz but saying that, for the purposes of logic worlds could be anything at all. Kripke of course by 1963 had realised that worlds did not have to be models, as work by authors like Kanger had supposed, but (Bayart 1958) explicitly denies that they should be models. In 1959 Bayart produced a Henkin completeness proof for quantificational S5. An English translation of Bayart's two papers, using more familiar notation and with an historical introduction and a commentary is found in Cresswell (2015). (See also Cresswell 2016.)

\section{Conclusion}

Until the work of Kripke and others in the late 1950s and early 1960s modal logic was frequently faulted through not having a viable semantic theory comparable to that produced for standard propositional and predicate logic. We have seen that Feys invokes the axiomatic method in modal logic precisely to compensate for this lack. What the possible-worlds semantics does reveal is that it is the fact that modal logic has such a simple and intuitive metatheory which goes a long way to explaining just why it survived for so long even when its critics felt that it was uninterpretable. ${ }^{26}$

\footnotetext{
${ }^{25}$ It should be noted that the present survey has concerned itself solely with modal propositional logic. The early developments in modal predicate logic begin with those found in (Barcan 1946; 1947) and elsewhere.

${ }^{26}$ The following list of references contains all the articles referred to in the text, together with other early articles. It does not claim to be a complete bibliography of work in modal logic before the late 1950 s.
} 


\section{References}

Barcan (Marcus), Ruth C. 1946. "A Functional Calculus of First Order Based on Strict Implication." The Journal of Symbolic Logic 11(1): 1-16. https://doi.org/10.2307/2269159

Barcan (Marcus), Ruth C. 1947. "The Identity of Individuals in a Strict Functional Calculus of Second Order." The Journal of Symbolic Logic 12(1): 12-15. https://doi.org/10.2307/2267171

Bayart, Arnauld. 1958. "La Correction de la Logique Modale du Premier et Second Ordre S5." Logique et Analyse 1(1): 28-45.

Bayart, Arnauld. 1959. "Quasi-adéquation de la Logique Modale de Second Ordre S5 et Adéquation de la Logique Modale de Premier Ordre S5." Logique et Analyse 2(6-7): 99-121.

Becker, Oskar. 1930. "Zur Logik der Modalitäten." Jahrbuch für Philosophie und Phänomenologische Forschung 11: 497-548.

Bergmann Gustav. 1949. "The Finite Representations of S5." Methodos 1: 217-219.

Carnap, Rudolf. 1946. "Modalities and Quantification." The Journal of Symbolic Logic 11(2): 33-64 https://doi.org/10.2307/2268610

Carnap, Rudolf. 1947. Meaning and necessity. Chicago: University of Chicago Press.

Cresswell, Max. 2013. "Carnap and McKinsey: Topics in the Pre-history of Possible Worlds semantics." In Proceedings of the 12th Asian Logic Conference, edited by J. Brendle, R. Downey, R. Goldblatt and B. Kim, pp. 53-75.

https://doi.org/10.1142/9789814449274_0003

Cresswell, Max. 2015. "Arnould Bayart's Modal Completeness Theorems: Translated with an Introduction and Commentary." Logique et Analyse 58(229): 89-142. https://doi .org/10.2143/LEA.229.0.3089909

Cresswell, Max. 2016. "Worlds and Models in Bayart and Carnap." Australasian Journal of Logic 13: 1-10. https://doi.org/10.26686/aj1.v13i1.3927

Dugundji, James. 1940. "Note on a Property of Matrices for Lewis and Langford's Calculi of Propositions." The Journal of Symbolic Logic 5: 150-151. https://doi.org/10.2307/2268175

Feys, Robert. 1937. "Les Logiques Nouvelles des Modalités." Revue Néoscholastique de Philosophie 40: 517-553 and 41: 217-252. https://doi.org/10.2307/2267606

Feys, Robert. 1950. Les systèmes Formalisés Aristotéliciennes." Revue Philosophique de Louvain 48: 478-509.

Feys, Robert. 1965. Modal Logics. Louvain: E. Nauwelaerts.

Gödel, Kurt. 1931. Review of Becker 1930. Monatshefte für Mathematik und Physik 38: A5-A6.

Gödel, Kurt. 1933. "Eine Interpretation des intuitionistischen AussagenKalüls." Ergebnisse eines math. Kolloquiums, Heft 4, 39-40.

Halldén, Sören. 1949. "A Reduction of the Primitive Symbols of the Lewis Calculi." Portugaliae Mathematica 8: 85-88.

Organon F 26 (3) 2019: 323-339 
Halldén, Sören. 1950. "Results Concerning the Decision Problem of Lewis's Calculi S3 and S6." The Journal of Symbolic Logic 14: 230-236. https://doi .org/10.2307/2269232

Heyting Arend. 1930. "Die formalen Regeln der intuitionistischen Logik." Sitzungsber. Preuss. Akad. Wiss. (Phys.-math. Klasse), 42-56.

Hilbert, David, and Ackermann, Wilhelm. 1928. Grundzüge der Theoretischen Logik. Berlin, Julius Springer. The English translation of the second (1938) edition was published as Principles of Mathematical Logic, 1950, New York: Chelsea Publishing Company.

Kanger, Stig. 1957. Provability in Logic. Stockholm: Almqvist and Wiksell.

Kripke, Saul A. 1959. "A Completeness Theorem in Modal Logic." The Journal of Symbolic Logic 24(1): 1-14. https://doi.org/10.2307/2964568

Kripke, Saul, A. 1963. "Semantical Analysis of Modal Logic I. Normal Propositional Calculi." Zeitschrift für mathematische Logik und Grundlagen der Mathematik 9(5-6): 67-96. https://doi.org/10.1002/malq.19630090502

Lewis, Clarence Irving. 1912. "Implication and the Algebra of Logic. Mind 21(84): 522-31. https://doi.org/10.1093/mind/XXI.84.522

Lewis, Clarence Irving. 1913. "Interesting Theorems in Symbolic Logic." Journal of Philosophy 10(9): 239-42. https://doi.org/10.2307/2012471

Lewis, Clarence Irving. 1914a. "The Calculus of Strict Implication." Mind 23(90): 240-247. https://doi.org/10.1093/mind/XXIII.1.240

Lewis, Clarence Irving. 1914b. "The Matrix Algebra for Implication." Journal of Philosophy 11(22): 589-600. https://doi.org/10.2307/2012652

Lewis, Clarence Irving. 1918. A Survey of Symbolic Logic. Berkeley: University of California Press, (N.B. The chapter on strict implication is not included in the 1961 Dover reprint) https://doi.org/10.2307/2940598

Lewis, Clarence Irving. 1920. "Strict Implication. An Emendation." Journal of Philosophy 17(11): 300-302.

Lewis, Clarence Irving, and Langford, Cooper Harold. 1932. Symbolic Logic. New York: Dover.

McColl, Hugh. 1906. Symbolic Logic and its Applications. London: Longmans Green.

McKinsey, John C.C. 1934. "A Reduction in the Number of Postulates for C.I. Lewis' System of Strict Implication." Bulletin of the American Mathematical Society 40(6): $425-427$.

McKinsey, John C.C. 1941. "A Solution of the Decision Problem for the Lewis Systems S2 and S4 with an Application to Topology." The Journal of Symbolic Logic 6(4): 117-134. https://doi .org/10.2307/2267105

McKinsey, John C.C. 1944. "On the Number of Complete Extensions of the Lewis Systems of Sentential Calculus." The Journal of Symbolic Logic 9: 41-45.

McKinsey, John C.C. 1945. "On the Syntactical Construction of Systems of Modal Logic." The Journal of Symbolic Logic 10: 83-96 
McKinsey, John C.C., and Tarski, Alfred. 1944. "The Algebra of Topology." Annals of Mathematics 45: 141-191.

McKinsey, John C.C., and Tarski, Alfred. 1948. "Some Theorems about the Sentential Calculi of Lewis and Heyting." The Journal of Symbolic Logic 13: 1-15. https://doi.org/10.2307/2268135

Nelson, Everett J. 1930. "Intensional Relations." Mind 39(156): 440-453. https://doi.org/https://doi.org/10.1093/mind/XXXIX.156.440

Parry, William T. 1933. "Zum Lewisschen Aussagenkalkül." Ergebnisse eines Math. Koll., Heft 4, pp. 15-16.

Parry, William T. 1934. "The Postulates for 'Strict Implication'." Mind 43(169): 78-80. https://doi.org/https://doi.org/10.1093/mind/XLIII.169.78

Parry, William T. 1939. "Modalities in the Survey System of Strict Implication." The Journal of Symbolic Logic 4(4): 131-54. https://doi.org/10.2307/2268714

Parry, William T. 1968. "The Logic of C.I. Lewis." In Schilpp 1968, 115-154.

Prior, Arthur N. 1951. "The Ethical Copula." Australasian Journal of Philosophy 29: 137-154. Reprinted in Prior 1976, 9-24. https://doi .org/10.1080/00048405185200171

Prior, Arthur N. 1952. "In what Sense is Modal Logic Many-valued?" Analysis 12(6): 138-143. https://doi .org/10.2307/3326976

Prior, Arthur N. 1955. Formal Logic. Oxford: Oxford University Press. (Second Edition: 1962)

Prior, Arthur N. 1957. Time and Modality. Oxford: Oxford University Press.

Prior, Arthur N. 1967. Past, Present and Future. Oxford: Clarendon Press.

Prior, Arthur N. 1976. Papers in Logic and Ethics. London: Duckworth.

Reichenbach, Hans. 1954. Nomological Statements and Admissible Operations. Amsterdam: North-Holland.

Schilpp, Paul A. (ed.) 1968. The Philosophy of C.I. Lewis. La Salle: Open Court.

Surma, Stanisław J. (ed.) 1977. Mordchaj Wajsberg: Logical Works. Wroclaw: Polish Academy of Sciences, Institute of Philosophy and Sociology.

Wajsberg, Mordchaj. 1933. "Ein erweiteter Klassenkalkül." Monatshefte für Mathematik und Physik. 40: 113.-126. (Translated as: "An extened class calculus", in (Surma 1977), pp. 50-61.)

Whitehead, Alfred N., and Russell, Bertrand. 1910. Principia Mathematica. Cambridge: Cambridge University Press. Three volumes. First edition 1910-1913. Second edition 1923-1927.

Wiener, Norbert. 1916. "Mr. Lewis and Implication." The Journal of Philosophy, Psychology and Scientific Methods 13(24): 656-662. https: //doi .org/10.2307/2013531

von Wright, Georg H. 1951a. "Deontic Logic." Mind 60(237): 1-15. https://doi.org/10.1093/mind/LX.237.1

von Wright, Georg H. 1951b. An Essay in Modal Logic. Amsterdam: North Holland.

Organon F 26 (3) 2019: 323-339 